\title{
i[글
}

\section{Quality Management and Change Management Implementation-A Study of Construction Firms in Nigeria}

\author{
Constance Ehiozee \\ Alphamead Group, Nigeria
}

\begin{abstract}
Nigeria construction industry today has fast seen a rapid growth with entry of multinational construction firms and a rise in certification of most indigenous firms to a quality management standard. However, despite these certifications, the big question remains- are these companies implementing the quality management systems requirements and embedding change management strategies. The main aim of this study was to establish the relationship between quality management and change management implementation on main factors of construction projects in Lagos, Nigeria. In order to achieve these, several semi-structured interviews were conducted with the construction quality Leaders and change managers. The following phase consisted in developing a questionnaire, based on the literature review from different books, journals, and websites, in order to understand profoundly quality management system and change management, and on the main contributions of the semi-structured interviews. This questionnaire was sent to all 20 Nigerian construction companies certified according to the ISO 9001 standard. Finally, the analysis of data was accomplished by descriptive statistics to find the results and conclusion. The findings revealed that the management of change is the most important challenge for organizations, a lack of understanding of the management of particular changes, which further resulted in the failure of management systems, programs, tools and standards related to quality further emphasized the relationship between change management and quality management. In view of the findings, it was recommended amongst others that the change management system integrates quality to provide a real-time quality benchmark at every step of the process from planning design through construction and post construction phase.
\end{abstract}

Keywords: Quality, Change management, Management systems, Construction, QMS 